\title{
Integrating Canadian Youth: The State of Intergroup Contact, Belonging, and Support for Immigration
}

\author{
Lily Kaufmann ${ }^{1}$ \\ University of Manitoba, Canada
}

\begin{abstract}
This paper reports the results of a survey examining 168 immigrant and non-immigrant youth's perspectives of intergroup relations, support for immigration, and feelings of belonging in Canada. Using Allport's (1954) contact theory and the multiculturalism hypothesis (Berry et al., 2021) as a framework, the data is analyzed in the context of relative levels of intergroup contact, friendship, immigration-related knowledgeability, and perceived diversity. This study finds that, overall, the Canadian youth surveyed were more supportive of immigration than older generations and reported high levels of intergroup positivity and frequent intergroup contact. Moreover, intergroup contact and intergroup friendships were positively associated with feelings of belonging, whereas support for immigration was associated with immigration-related knowledgeability and perceptions of diversity.
\end{abstract}

Keywords: belonging, immigration, integration, intergroup contact, youth.

Although immigrants are a vital component of Canada's social, cultural, and economic life, they are not always met with acceptance; according to a recent poll, half of Canadians feel that immigrants are not "adopting Canadian values" and over a third believe there is "too much" immigration in Canada (Neuman, 2019). Resistance to immigration may be exacerbated as the source countries of immigration change, with increasing numbers of immigrants from African and Asian countries and reducing European immigration (Statistics Canada, 2017a). As the ethnocultural demographics of immigration, and Canada more generally, evolve, promoting positive intergroup relationships between different cultural groups and addressing resistance to ethnocultural diversity is crucial.

Integration, in which immigrants are encouraged to maintain their culture of origin and develop social relationships with different ethnocultural groups, is widely understood as the best path for promoting intergroup harmony, social cohesion, and wellbeing (Berry et al., 2021; Hou et al., 2016; Pettigrew \& Tropp, 2006). Although Canada officially endorses integration, Canadian policy and discourse often reflect assimilationist perspectives, in which immigrants are encouraged to adopt the mainstream culture (Kaufmann, 2021; Naffi, 2017). The tendency towards an assimilationist perspective is reflected in integration literature, which tends to focus on the ways in which immigrants adapt to mainstream culture but rarely examines how members of the dominant society cope with changes in their cultural landscape (Berry et al., 2021). Including non-immigrant perspectives is vital because integration is a bi-directional exchange of culture which challenges sociocultural norms and enriches the cultural lives of both dominant and non-dominant groups. As both immigrant and non-immigrant communities must collaborate to create an inclusive and

\footnotetext{
${ }^{1}$ Corresponding Author E-Mail: kaufman1@ myumanitoba.ca
} 
integrated society, "there is no longer any justification for looking at only one side of the intercultural coin in isolation from the other" (Berry et al., 2006, p. 732).

The Immigration in Canada: Youth Perspectives survey was created to address this gap in the literature and examines support for immigration and experiences of integration of immigrant and Canadian-born youth with the goal of identifying pathways to promote positive intergroup relationships. Youth were chosen as the population of focus for this study as youth voices are often excluded from discourse on immigration and integration, even though over $40 \%$ of Canadians are either first- or second- generation immigrants, and youth ( $<24$ years old) comprise one sixth of all Canadian newcomers (Statistics Canada, 2017b). Including youth perspectives is crucial, as youth are often still forming ideological beliefs and research on youth perspectives may provide insight into future public opinion and support for immigration policy.

This study examines the perspectives of 168 youth (16-17) from across Canada to capture a snapshot of the status of youth's intergroup (i.e. immigrant-non-immigrant) relations to answer three core research questions: (a) how integrated are Canadian youth? (b) what factors predict integration/belonging? (c) what factors are associated with support for immigration? Specifically, the study will capture a snapshot of youths' intergroup contact, feelings of belonging, and perspectives on immigration, and will analyze the influence of intergroup contact, knowledge, and perceived diversity on rates of integration and support for immigration. The responses of immigrant and non-immigrant youth are compared, documenting the relative rates of integration among participant groups.

\section{Integration}

Integration - defined as the bi-directional sharing of culture, in which individuals maintain aspects of their own culture while engaging in social relationships with other ethnocultural individuals or groups - is associated with increased success, wellbeing, and higher levels of happiness for both newcomers and existing community members and is believed to be the best strategy to increase social harmony (Berry \& Hou, 2017; Berry et al., 2006; Berry et al., 2021; Cohen, 2016). Canada promotes integration as the official acculturation style and explicitly describes the right to integration in the Multiculturalism Act and the Immigrant and Refugee Protection Act, recognizing that, "integration involves mutual obligations for new immigrants and Canadian society" (Immigration and Refugee Protection Act, 2001, Art. 3(1)(e); Canadian Multiculturalism Act, 1988). Nonetheless, the term "integration" is often used incorrectly by researchers, policymakers, and the Canadian public to connote unilateral cultural change required by newcomers, ignoring the responsibilities of the settled community (Kaufmann, 2021; Naffi, 2017). In this way, "integration" and "assimilation" have been conflated in national dialogue: integration is stated but, often, assimilative practices are endorsed (Naffi, 2017).

\section{Intergroup Contact}

Addressing prejudice and anti-immigrant perspectives held by the settled community is a vital component of integration, as attitudes towards immigrants influence immigration policy, social cohesion, and "the tone for intergroup relations more generally" (Esses, 2021, p. 505). Allport (1954) posits that negative attitudes towards a different social group - in the context of this study, against immigrants - can be ameliorated through intergroup contact, in which individuals interact with people from the other social group. However, it is vital to consider the context and quality of contact, as not all contact promotes positive perceptions, and negative contact has the 
possibility to negatively affect intergroup relations (Esses, 2021; Robinson et al., 2020). For example, Kiehne's (2019) research on anti-immigrant prejudice in university students provides evidence linking intergroup contact with reduced anti-immigrant prejudice. However, Kiehne's and Ayon's (2016) earlier study with adult participants showed that the positive effect of immigrant-non-immigrant friendships did not "moderate or buffer" anti-immigrant prejudice associated with individuals who hold conservative political ideologies, indicating that political beliefs may outweigh the positive effects of intergroup friendship (p. 135). Thus, contact-based interventions may function better among youth, who are still forming some ideological beliefs.

This study focuses on intergroup contact in the school setting, as schools meet many of Allport's (1954) conditions for positive intergroup contact: equal status, intergroup cooperation, institutional support, and common goals. Despite this, there is significant discrimination in this context, with research indicating a quarter of youth experience discrimination from peers and 14\%$37 \%$ from teachers (Cohen, 2016; Gallucci, 2016). The prevalence of discrimination suggests that there is a need for prejudice reduction, for both educational staff and students. Contact-based interventions may be one method for promoting positive intergroup relationships and addressing anti-immigrant and ethnic prejudices, and would require the promotion of positive contact, which does not always occur organically, even in diverse environments (Bernstein \& Salipante, 2017; Kiehne, 2019).

\section{Ethnocultural Diversity and Perceptions of Threat}

Perceptions of threat may be one possible explanation for resistance to intergroup contact and integration. Threat perceptions have been linked with support for restrictive immigration policy and assimilation, in which the dominant culture is preserved and adopted by new members (Callens et al., 2019; Jimenez et al., 2021). Recent polls suggest that immigration is triggering feelings of threat among Canadians: a third of adults are worried that immigrants pose economic competition, and almost $70 \%$ believe that their demographic does not have enough political power and that their cultural values are "losing ground" (Angus Reid, 2019a, 2019b; Smith, 2019). Ethnoculturally diverse immigration may be particularly likely to trigger perceptions of threat, as compared to immigration from culturally familiar and demographically similar regions (Esses, 2021; Robinson et al., 2020). In addition, media framing of immigration has been shown to influence perceptions of threat. Media with metaphors of immigrants arriving in "floods" and "waves", and disproportionate coverage of negatively valanced stories (e.g., crime, unemployment rates) have been shown to promote perceptions of threat and anti-immigrant perspectives (Jimenez et al., 2021; Wallace, 2018).

While Canadians overwhelmingly support multicultural rhetoric, xenophobia and racism remain present in our society (Berry \& Hou, 2017; Government of Canada, 2020). The link between ethnic diversity and immigration leads to a de facto system of segmented assimilation, in which certain ethnocultural groups are discouraged from embracing their culture of origin while others are celebrated. Segmented assimilation is illustrated by the rates of discrimination in Canada: nearly four times as many visible minority immigrants report experiencing discrimination than European, non-visible minority immigrants (Reitz \& Banerjee, 2007). Due to the interrelated nature of immigration and ethnic diversity, and the existence of discrimination and ethnocentrism, prejudice reduction within Canadian communities must be a cornerstone of integration research, policy, and praxis. 


\section{Belonging}

A Statistics Canada study tested the feasibility of multiculturalism by measuring feelings of belonging among Canadian immigrants and found that it was possible to have integrated belonging, a sense of belonging in Canada while maintaining a sense of belonging with country of origin (Hou et al., 2016). The authors argue that because culture and behaviour vary between immigrant groups, "belonging transcends ethnicity and culture" and is therefore a better measure of integration (p. 10). Between $70 \%-75 \%$ of second-generation immigrants have achieved integrated belonging, with visible minorities reporting the highest rates of integration (Berry \& Hou, 2017; Hou et al., 2016). Feelings of belonging in Canada were significantly predicted by age of immigration, time in Canada, and speaking English or French in the home. Experiences of discrimination (more often experienced by racial minorities), and low socioeconomic status were associated with less national belonging, lower rates of life satisfaction, and mental health challenges (Berry \& Hou, 2017; Hou et al., 2016). These studies describe the integration of immigrants; similar research is recommended to better understand the factors that contribute to non-immigrant Canadians' experiences of belonging.

\section{Conceptual Framework}

This paper uses intergroup contact theory and the multiculturalism hypothesis as a framework through which to explore the intergroup relations of Canadian youth. These theories are the cornerstone of cross-cultural research and have been used to understand and address the challenges of social harmony in culturally diverse societies around the world (Berry et al., 2021). Allport (1954) posited that positive social contact between distinct social groups has positive effects on intergroup positivity. In the context of immigration, research has found that intergroup contact is effective in promoting positive intergroup relationships in a wide range of social and national contexts (Berry et al., 2021). Friendships are thought to be a particularly effective form of contact, as friendships meet the conditions that optimize the positive effects of contact and have been found to be effective in reducing prejudice and promoting intergroup positivity (Pettigrew et al., 2011). Positive contact experiences with immigrant or ethnocultural minority groups have been associated with support for inclusive immigration policy (Kiehne, 2019). This paper evaluates current levels of intergroup contact and explores the relationship between the frequency and quality of social contact on perceptions of immigration and feelings of belonging.

In addition, this paper explores factors which may influence willingness to engage in intergroup contact. Multiculturalism theory posits that individuals or groups that feel secure of their place in society are more willing to accept diversity; conversely, perceptions of threat decrease willingness to accept diversity (Berry et al., 2021). Specific to immigration, perceptions of threat have been found to be associated with anti-immigrant prejudice and support for restrictive immigration policy (Jimenez et al., 2021; Kiehne, 2019). As immigration has the potential to trigger feelings of symbolic threat (e.g., perceived threat to values and belief systems) and/or real threat (e.g., perceptions of threat to economic, demographic, or political power), mitigating perceptions

of threat is an important aspect of promoting positive intergroup relations (Esses, 2021; Stephan \& Renfro, 2002). To examine the role of threat, this study analyzed the relationship between perceptions of diversity and levels of immigration-related knowledgeability on the perceived quality of intergroup relations and support for immigration. 


\section{Methods}

\section{Research Design}

This research project was designed with the intention of engaging youth and was conducted to comply with distancing regulations during the COVID-19 pandemic. The survey was completed in a novel "chat" format to promote youth engagement using Rival Technology's "Chat Lab" software that presented survey questions one at a time, formatted as a text conversation, to encourage youth engagement. The survey was divided into four conversations to reduce survey fatigue, and invitations to new chats were sent every 2-3 days. In this survey, the term "immigrant" was not defined, as the survey assessed perspectives of immigration, in whichever way the term was understood by participants. Prompting youth to use a self-defined understanding of immigration was useful because the term immigrant has diverse definitions in Canadian discourse: this study assessed the psychological relationship with immigrants as they are understood by the general population. To promote accessibility for students of varying language abilities, the survey was written at a 6th grade reading level (tested by Flesh-Kincaid Grade Level and Gunning Fog Index); the responses to qualitative questions suggest that participants understood the survey.

\section{Data Collection}

Recruitment was conducted via paid Instagram advertisements. The advertisements were shown to youth aged 16-17 across Canada (except for Quebec, which does not allow those under 18 years of age to consent to research) for three weeks (September 10, 2020-October 1, 2020). At the end of the first chat, following the demographic questions, the survey included an item that allowed participants to self-identify as "new" or "settled" Canadians, as these terms are subjective and are a function of personal identity. The following description was provided: "New Canadians moved to Canada from another country. Settled Canadians were born in Canada or moved to Canada when they were very young." After reading the description, 17 participants identified as new Canadians, none of which identified as "refugees" in a follow-up question. The remaining (n = 149) participants identified as settled Canadians. Following the self-identification question, "new" and "settled" participants were provided different versions of the second chat, with the language altered to describe intergroup relations for both groups. For example, settled Canadians received the question: “... how often do you talk with new Canadians at school?" and new Canadians received: "...how often do you talk with settled Canadians at school?". Both groups completed identical versions of the third and fourth chat, as these chats did not include questions regarding intergroup relations.

\section{Participants and Sampling}

A total of 222 participants completed at least some part of the survey, $\mathrm{N}=168$ participants completed the first three chats, and $\mathrm{N}=144$ participants completed the fourth chat, which included open-response questions, resulting in an attrition rate of $24 \%$ for the first three chats and $35 \%$ for the final chat. Participants were youth aged 16 (40\%) and 17 (60\%) from across Canada; 78\% of participants identified as female, $13 \%$ as male, and $10 \%$ preferred to self-describe or not disclose gender.

Of the participants who answered the settled Canadian chat, 24 listed a country of birth other than Canada. This led to three participant groups, formed on the basis of immigrant status 
and self-identification: (a) Canadian-born ( $\mathrm{n}=125)$ : born in Canada, self-defined as settled; (b) new immigrants $(\mathrm{n}=17)$ : born outside of Canada, self-identified as new; and (c) settled immigrants $(\mathrm{n}=24)$ : born outside of Canada, self-identified as settled. Two participants in the settled Canadian chat declined to provide country of birth and therefore were not sorted in participant groups, resulting in $\mathrm{N}=166$ for all questions analyzed by participant group. The immigrant participants in this study can be considered " 1.5 generation" as they immigrated to Canada before adolescence: new immigrant participants reported having spent between 5 to 16.5 years in Canada, and settled immigrants reported 10 to 16.5 years.

The proportion of participants who speak English as a first language varied between participant groups: approximately a third (29\%) of new immigrants, half (46\%) of settled immigrants, and most (90\%) of settled Canadians reported English as a first language (see Table 1). Ethnicity also varied between groups. Under the Employment Equity Act and the Statistics Canada definition (2020) of visible minorities as ethnicities other than Indigenous or White, $9 \%$ of Canadian-born participants, $63 \%$ of settled immigrants, and $65 \%$ of new immigrants self-identified as visible minorities. Further disaggregating this data, $17 \%$ of the Canadian-born and $8 \%$ of the settled-immigrant participants identified as Indigenous. The high proportion of Indigenous participants in this survey, as compared to Canadian population overall, suggests there may be a high level of interest in immigration issues among Indigenous youth. While the scope of this study is on the relations between immigrant youth and the non-immigrant population as a whole (including both Indigenous and settled Canadians), further investigation into Indigenous youths' perspectives is recommended.

Table 1

Participant Demographics

Participants $\quad$ English as a First $\quad$ Visible Minorities

Language

\begin{tabular}{l|ccc}
\hline Canadian-born & 125 & $90 \%$ & $9 \%$ \\
New Immigrant & 17 & $29 \%$ & $65 \%$ \\
Settled Immigrant & 24 & $46 \%$ & $63 \%$ \\
\hline
\end{tabular}

Due to the relatively small sample size of this study, analysis of different ethnic groups as a function of their immigration status was not conducted. Results must be interpreted recognizing that the perceptions of immigration among Canada's Indigenous population are likely influenced by the historical legacy of colonization. Additionally, it is crucial to recognize that immigrants' experiences of immigration are often linked with visible minority status and that the marginalization of visible minority groups is one of the barriers faced by many immigrants in Canada.

\section{Data Analysis}

Qualitative and quantitative data was analyzed using SPSS. One-way ANOVA and chisquared tests were conducted to measure significant differences between participant groups for continuous and categorical variables, respectively. Multivariate regression analyses were conducted to test for predictors of belonging, support for immigration, and friendliness of intergroup relations. Pearson correlation analyses were used to conduct exploratory analyses on belonging and perceptions of diversity. The composites intergroup contact and immigrant-related 
knowledgeability were used as grouped independent variables to measure their predictive power of belonging and support for immigration.

Five items were used to measure intergroup contact: (a) frequency of intergroup contact (e.g., “...how often do you talk to [new/settled] Canadians at school?"); (b) quality of personal intergroup contact (e.g., "...thinking about YOUR interactions with [new/settled] Canadians at school, are they...?); (c) quality of intergroup relations in participants' schools (e.g., "In general, how would you describe the relationship between settled Canadians and new Canadians in your high school?"); (d) number of interethnic friendships (e.g., "How many of your close friends are of a different ethnicity/culture than you?"); and (e) majority of intergroup friendships (e.g., "Are most of your friends...?"). The first three items were measured on a 5-point scale from -2 to 2 . Frequency of contact was measured from "never" to "always" and the quality of intergroup contact and relations measured from "very unfriendly to very friendly". The question regarding interethnic friendship question was an open response, and the intergroup friendship question was dichotomous: participants responded that most of their friends are "new Canadians" or "settled Canadians".

The knowledgeability composite included the sources of immigrant-related information (e.g., "Where do you get your information about immigration from?"), self-perception of being informed about immigration (e.g., "Do you feel informed (that you understand) about Canadian immigration?"), and openness to learning more about immigration (e.g., "Are you interested in learning more about Canadian immigration?"). There were 17 options for source of immigrationrelated information (e.g., school, TV, social media, friends, and family), and the other two items were dichotomous (e.g., yes, no).

\section{Results}

\section{Intergroup Contact}

Immigrant and Canadian-born youth both reported frequent and friendly intergroup contact. Nearly all (96\%) of all participants rated their personal intergroup interactions as somewhat or very friendly. Despite the ubiquity of friendly personal interactions, fewer youth $(85 \%)$ perceived intergroup relations in their schools more generally as friendly. A one-way ANOVA found no significant difference in the perceived friendliness of intergroup contact between new immigrant $(M=1.5, S D=0.8)$, settled immigrant $(M=1.5, S D=0.5)$, and Canadian-born youth $(M=1.7, S D$ $=0.7) F(2,160)=0.59, p=0.558$. There was no significant difference when considering the reported friendliness of intergroup relations in schools more generally $F(2,147)=0.72, p=.487$, such that new immigrant, settled immigrant, and Canadian-born youth reported similar levels of friendliness $(M=1.3 ; S D=1.0, M=1.6, S D=0.8$, and $M=1.4 ; S D=0.8$, respectively $)$. New immigrant, settled immigrant, and Canadian-born participants reported moderate levels of intergroup contact $(M=0.5 ; S D=1.0, M=-0.2 ; S D=1.2, M=0.5 ; S D=1.3$, respectively). A one-way ANOVA found no significant differences in frequency of intergroup contact between participant groups $F(2,136)=6.26, p=.137$.

Although youth reported similar numbers of inter-ethnic friendships, immigrant participants were more likely to have intergroup (i.e. immigrant-non-immigrant) friendships. A one-way ANOVA found no significant difference in the mean number of inter-ethnic friendships, $F(2,161)=6.19, p=.726$. Participants reported between $M=5.3-6.0(S D=2.6-3.5)$ inter-ethnic friendships. When asked about intergroup friendships, the majority of new $(82 \%)$ and settled immigrants (71\%) reported that most of their friendships are with settled Canadians (i.e. intergroup). However, only $6 \%$ of Canadian-born participants reported that most of their 
friendships are with new Canadians. A chi-square test found that the difference in intergroup friendships is significant between participant groups $X^{2}(2, N=145)=93.10, p<.001$.

\section{Belonging}

A two-tailed Pearson correlation analysis was conducted to identify significant variables related to belonging including (a) personal characteristics; (b) social participation; (c) frequency and quality of intergroup contact; and (d) friendships (see Appendix A). The correlation matrix revealed that personal characteristics (first language, time speaking English, and time in Canada) were not significantly correlated with belonging. Belonging was positively correlated with social participation (frequency of intergroup contact and participation in extracurricular activities), quality of contact (perceived friendliness of personal interactions, intergroup relations in schools), and interethnic friendships. Overall, the findings indicate that belonging is associated with social integration - frequent and friendly intergroup contact, a diverse social circle, and participation in recreational activities - rather than personal characteristics (i.e. first language, participant group, time in Canada).

Multiple linear regression analyses were conducted to test for significant predictors of belonging. The first regression analysis was calculated to measure the predictive power of time in Canada/ age of immigration, first language, participant group, frequency of intergroup contact, and participation in extracurricular activities on belonging. A significant regression equation was found, $F(5,133)=2.32, p=.047$, with an $R^{2}=.08$. Of all of the variables tested, only intergroup contact emerged as a significant predictor of belonging, $\beta=.23, t(133)=2.85, p=.005,95 \% \mathrm{CI}$ $[.05, .30]$. A second multivariate linear regression analysis was run to test the predictive power of intergroup contact on belonging, using belonging as the dependent variable and variables related to intergroup contact (see composite variable definition) as predictors. A significant regression equation was found, $F(5,113)=5.03, p<.001$ with an $R^{2}=.18$. Frequency of contact $\beta=.20$, $t(113)=2.29, p=.024,95 \% \mathrm{CI}[.02, .27]$ and intergroup friendships $\beta=.18, t(113)=2.03, p=$ $.044,95 \%$ CI $[.01, .72]$ were significant predictors.

\section{Diversity}

In order to examine the relationship between perceived school diversity (measured by participants' estimated percentage of immigrants in their school) and intergroup contact, Pearson correlations between perceived diversity and the intergroup contact variables were conducted. No significant correlations were found. Originally, I intended to measure objective diversity, but as not all of the schools in our sample provided diversity information, this was not possible. However, existing research indicates that "it is the perceived size of immigrant populations, rather than their actual numbers" that influences perceptions of threat (Esses, 2021, p. 507).

To learn more about how perceived school diversity is related to perceptions of Canadian diversity more broadly, a second correlation analysis between perceived school diversity, perceived Canadian diversity, and the five intergroup contact variables was run. The only significant result was a positive correlation between perceived school diversity and perceived Canadian diversity $r$ $=.51, p<.001$ (see Figure 1). The results showed that intergroup contact is not correlated with perceptions of national or school diversity, although there was a sub-significant trend suggesting a negative correlation between school diversity and intergroup friendliness $r=-.14, p=.079$. This suggests that youths attending diverse schools are more likely to perceive Canada as a diverse 
country, while youth in less diverse communities may underestimate the proportion of the Canadian population that are immigrants.

Figure 1

Perceptions of Diversity

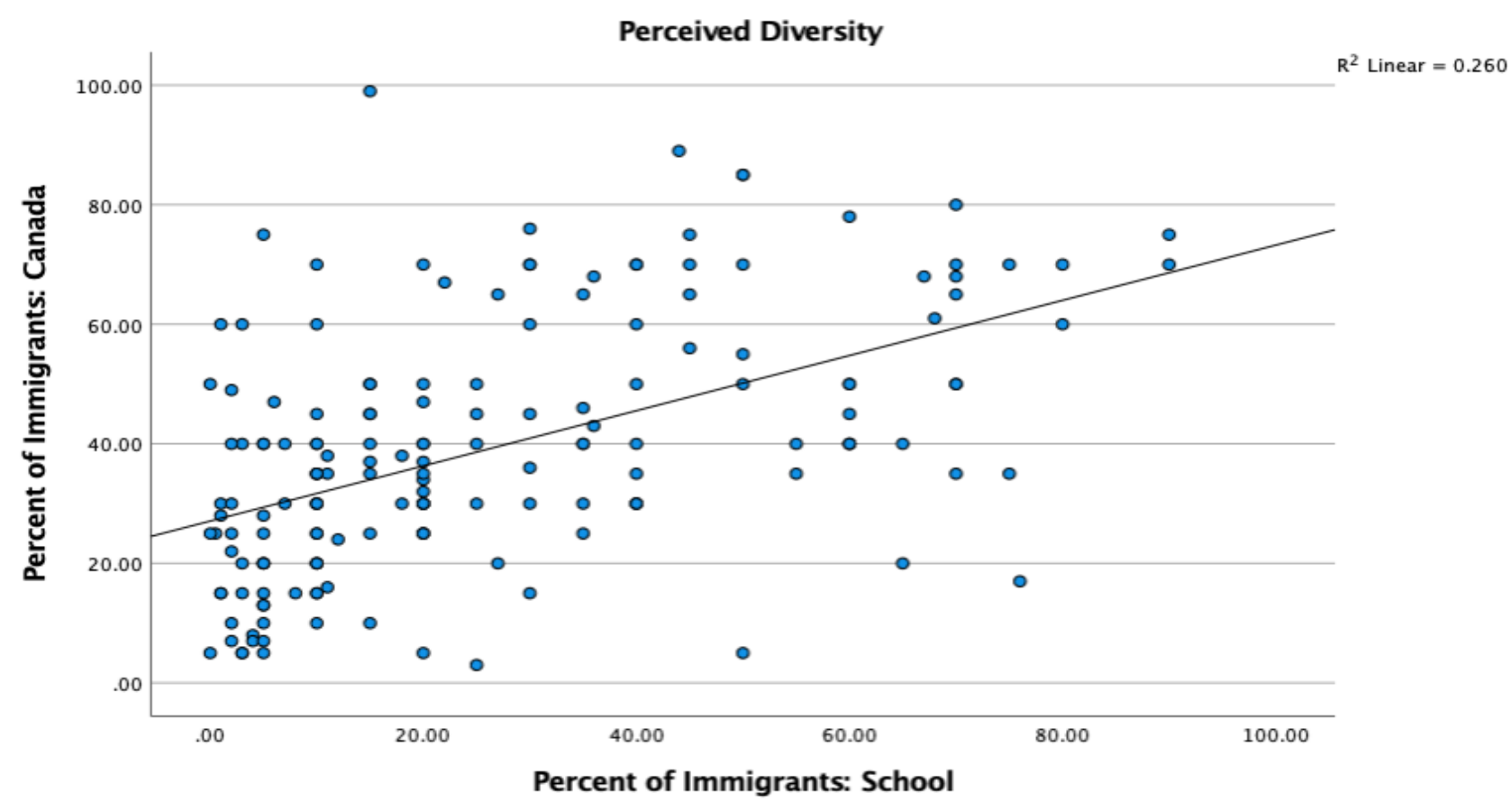

The perceived percentage of immigrants in Canada varied widely, from 3\%-99\%. Youth across all participant groups greatly overestimated the percentage of Canadians that are immigrants: over three quarters $(77 \%)$ of participants estimated higher than the national average (22\%) of first-generation immigrants (Statistics Canada, 2017b). While there is no significant difference in the mean perception of diversity in Canada across participant groups $(M=35-40, S D$ $=16-22)$, Canadian-born youth estimated a larger range of diversity (3\%-99\%) compared to new immigrants (5\%-61\%) and settled immigrants (13\%-80\%). Canadian-born participants also perceived higher levels diversity in their classrooms: while the mean estimates were $23 \%-28 \%$, and new immigrant youth estimated $2 \%-70 \%$, Canadian-born youth perceived that as many as $90 \%$ of their classmates were immigrants (0\%-90\%).

\section{Intergroup Relations}

Multiple regression analyses were conducted to examine the variables which predict the friendliness of intergroup relations in schools. The first regression analysis calculated the friendliness of intergroup relations in schools as the dependent variable and frequency of intergroup contact, school diversity, and friendliness of intergroup contact as the predictor variables. A significant regression equation was found $F(3,128)=16.13, p<.001, R^{2}=.27$. Of the variables tested, friendliness of personal interactions $\beta=.46, t(128)=5.92, p<.001,95 \% \mathrm{CI}[.35, .70]$ and school diversity $\beta=-.17, t(128)=-2.27, p=.025,95 \%$ CI $[-.01, .00]$ emerged as significant predictors. The data file was split by a participant group and no variables significant for settled 
immigrants. The friendliness of personal interactions was the only significant predictor $\beta=.46$, $t(95)=5.15, p<.001,95 \%$ CI $[.30, .67]$ for Canadian-born participants. Among new Canadians, significant predictors of belonging were friendliness of personal interactions $\beta=.59, t(11)=2.60$, $p=.025,95 \%$ CI $[.11,1.35]$ and perceived school diversity, $\beta=-.58, t(11)=-2.56, p=.027,95 \%$ CI $[-.05,-.00]$, which had nearly equal, but opposite, effects.

\section{Support for Immigration}

Overall, youth were supportive of immigration: when asked "Do you think Canada should receive more immigrants?", 60\%-70\% of participants said "yes", approximately 30\% were "not sure", and only small proportions of Canadian-born (7\%) and settled immigrant (4\%) participants answered "no" (see Figure 2). Multiple regression analyses were conducted to examine the roles of (a) intergroup contact; (b) level of diversity; (c) perception of immigrants; and (d) immigrationrelated knowledgeability in predicting support for immigration.

Figure 2

Should Canada Receive More Immigrants?

Settled Immigrants $\square$ New Immigrants

Settled Canadians

$80 \%$

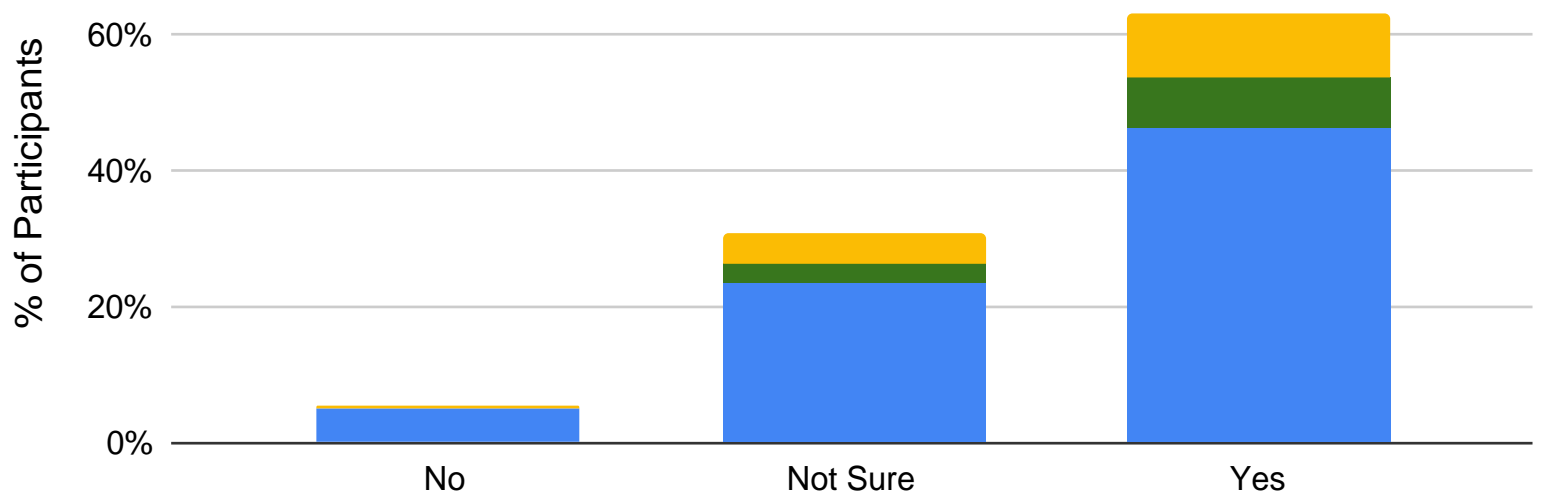

Participant Responses

\section{Intergroup Contact and Level of Diversity}

To test the role of intergroup contact, a multiple variable regression analysis was conducted with support for immigration as the dependent variable and intergroup contact variables as predictors. The regression analysis was non-significant $F(5,113)=.38, p=.859$, with an $R^{2}=.02$. A second regression analysis was conducted, with perceived school diversity and Canadian diversity as predictor variables. The analysis found a significant regression equation $F(2,162)=$ $3.36, p=.037$ with an $R^{2}=.04$. Perceived Canadian diversity emerged as the only significant predictor $\beta=-.18, t(162)=-2.06, p=.041,95 \% \mathrm{CI}[-.01,-.00]$. The results indicate that, for this sample of Canadian youth, higher perceived rates of immigrants in Canada predict less support for immigration. 


\section{Perception of Immigrants}

Participants were asked, "When you think about immigrants coming to Canada, who comes to mind first?". The answers were coded thematically, resulting in 21 categories converted into a Word Cloud to present the data (see Figure 3). In the instances that participants listed more than one category, only the first was used in order to capture the most salient image. These categories were grouped to facilitate data analysis into $10 \mathrm{key}$ themes. The file was split by support for immigration and the topline data revealed that participants who supported more immigration in Canada were the most likely to think of refugees or personal connections.

Youth who support immigration were twice as likely to think of a family member or friend $(22 \%)$ than those who were not sure (10\%). The salient image of a refugee was also positively related to support for immigration among youth: among those that supported more immigration, a third $(32 \%)$ pictured refugees, compared to a fifth $(19 \%)$ of the participants who were unsure. The participants who did not support more immigration in Canada never pictured personal connections or refugees, and exclusively described immigrants by region (Asian, Africa or the Middle East), or by "other" descriptors (i.e. religion). The majority of participants (89\%), across all participant groups, correctly identified that refugees flee from persecution. Most added that immigration, in comparison, is a "choice": refugees migrate out of necessity and immigrants actively choose to relocate.

\section{Figure 3}

\section{Perceptions of Immigrants}

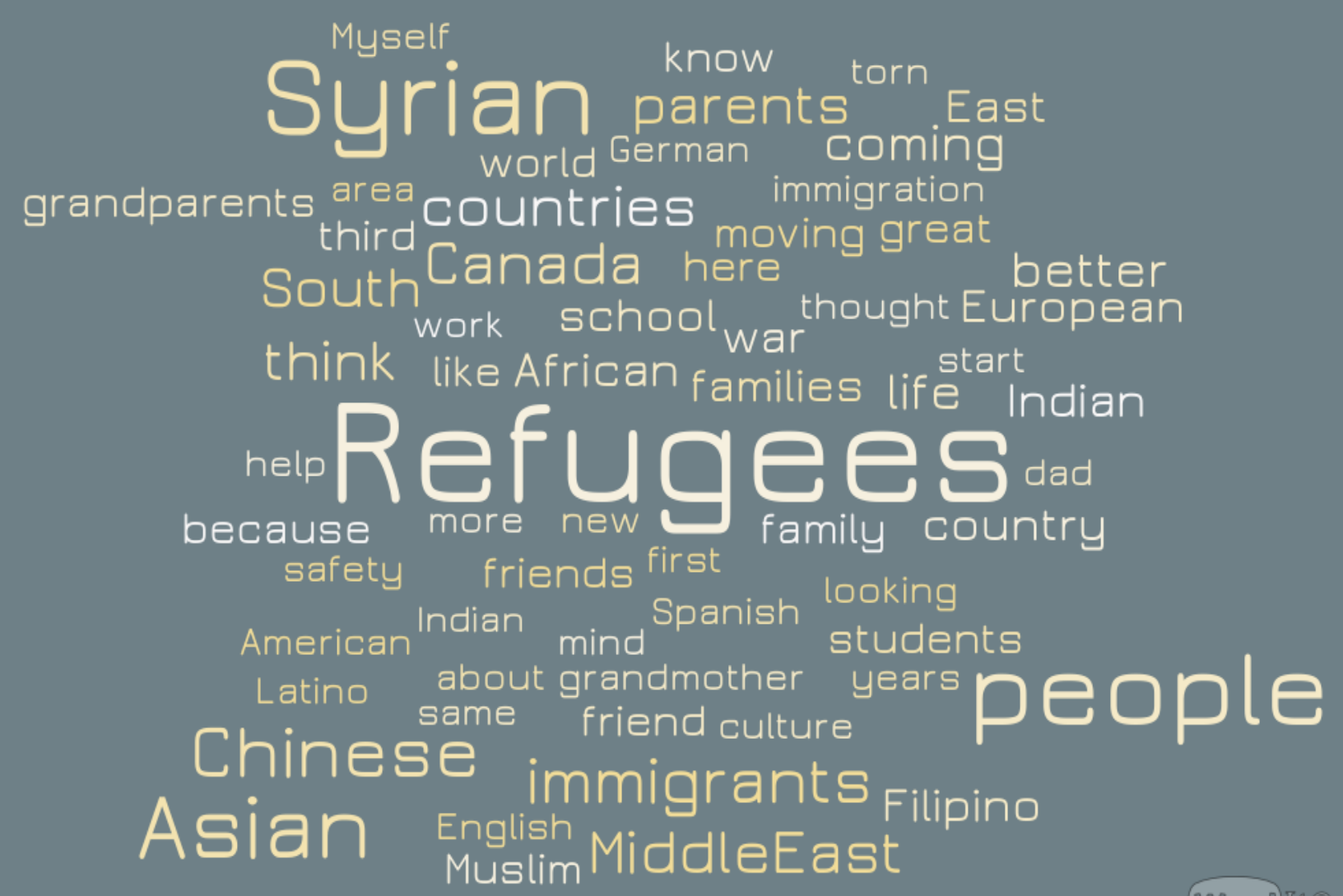

WOr@ 


\section{Knowledgeability}

To test immigration-related knowledgeability, participants were asked if they felt informed about Canadian immigration, if they were interested in learning more about immigration, and the sources of their immigration-related information. Between one-third and one half of youth feel informed about immigration in Canada, and the majority of youth sampled $(71 \%-88 \%)$ were interested in learning more. There were five main sources of information reported: (a) social media; (b) news; (c) school; (d) family and friends; and (e) talking with new Canadians. Nearly twice as many participants reported getting their information from social media than the news (see Figure 4). New immigrants were half as likely to get information from the news as Canadian-born participants and were more likely to get information from school than other participant groups.

\section{Figure 4}

Where are Canadian Youth Getting Their Immigration-related Information?

School

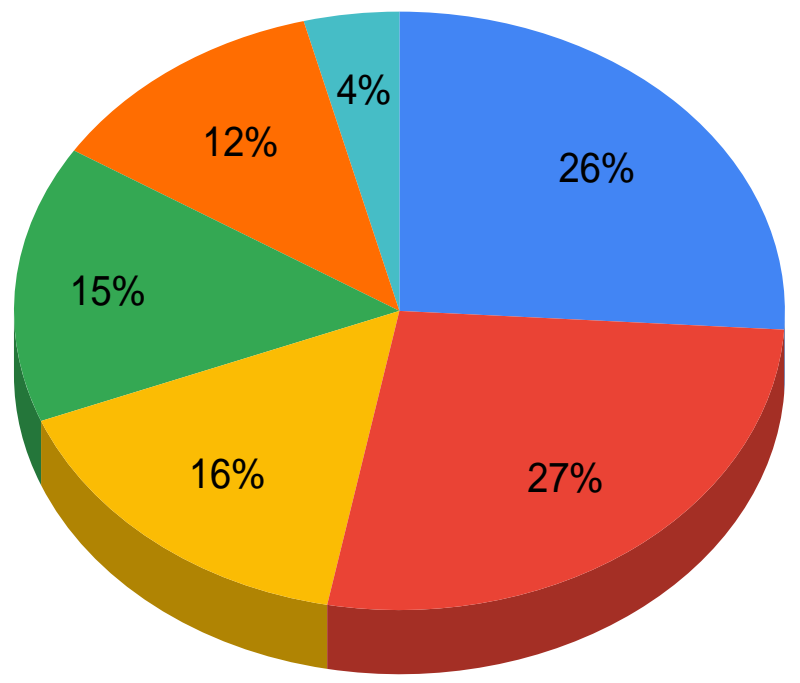

Social Media

News

Family and Friends

New Canadians

Other

A regression analysis was conducted to measure the self-perception of being informed, openness to learning, and source of information on support for immigration. A significant regression equation emerged $F(7,96)=2.21, p=.040$ with an $R^{2}=.14$. Significant predictors of support for immigration were openness to learning about immigration $\beta=.20, t(96)=2.00, p=$ $.048,95 \%$ CI $[.68, .00]$, learning about immigration from the news $\beta=-.19, t(96)=-2.01, p=$ $.048,95 \% \mathrm{CI}[-.51,-.00]$, and learning about immigration from social media $\beta=.21, t(96)=1.99$, $p=.049,95 \%$ CI $[.00,-.51]$. To follow up on the significant predictors of support for immigration, and to verify the direction of the effect, a linear univariate ANOVA test was run with support for immigration as the dependent variable and social media, news, and openness to learning as the fixed factors. The results were non-significant. A second univariate ANOVA test was run to examine the effect and interaction of the significant sources of information. The test revealed that while there was no significant interaction $F(1,164)=1.45, p=.230$, participants who learned about immigration from the news were significantly less likely to support immigration $(F(1,164)=5.58$, $p=.019)$, and confirmed that social media was linked with increased support for immigration $F(1$, $164)=3.98, p=.048$; see Figure 5). 


\section{Figure 5}

Estimated Marginal Means: Support for Immigration

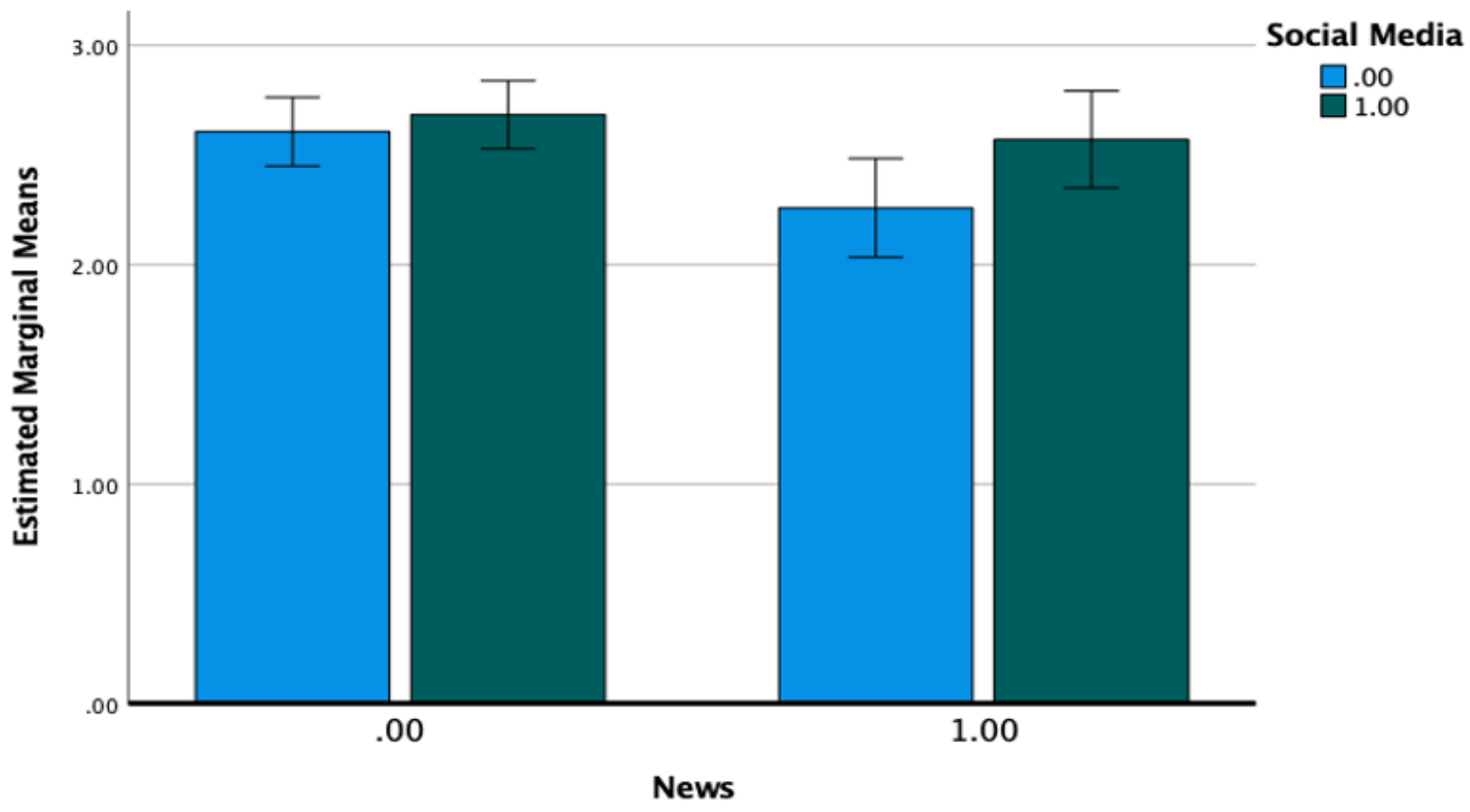

Error bars: $95 \% \mathrm{Cl}$

\section{Discussion}

The goal of this study was to evaluate of the efficacy of intergroup contact as a pathway for promoting positive intergroup relations, feelings of belonging, and support for immigration among Canadian youth. The results provided evidence supporting contact theory and the multiculturalism hypothesis. In this sample, contact and friendships between immigrant and Canadian-born youth were associated with feelings of belonging and support for immigration, while factors related to feelings of threat (i.e., perceptions of diversity) predicted lower levels of support for immigration. These findings suggest that interventions that promote intergroup contact and reduce perceptions of threat are promising pathway to promote social harmony and support for immigration in Canada and other multicultural societies.

Specifically, this study found that Canadian youth are well integrated. Overall, participants reported high levels of intergroup contact, and $96 \%$ perceived the contact as friendly. However, some authors argue that frequent and friendly, but superficial, contact does not necessarily promote multiculturalism, and friendships provide the opportunity for more meaningful contact (Robinson et al., 2020). In this study, immigrant youth were much more likely to report intergroup friendships than their Canadian-born peers, which suggests that immigrant youth are integrating successfully into Canadian society, but the majority of settled Canadian youth are not socially integrating with immigrants. Intergroup friendships, as well as frequency of intergroup contact and the perceived friendliness of intergroup relations predicted feelings of belonging, supporting Allport's (1954) contact theory and suggesting that social relationships are an effective pathway for promoting positive intergroup relationships between immigrant and settled populations. 
The results additionally suggest that there is a need to address feelings of threat and promote feelings of cultural security among the settled population. Perceptions of diversity significantly predicted less support for immigration, suggesting an association between feeling outnumbered and anti-immigrant attitudes. Relying on the news-which often frames immigration negatively (Jimenez et al., 2021; Wallace, 2018) — for immigration-related information was also linked with less support for immigration. In contrast, using social media for information was associated with higher levels of support for information. These findings suggest that personal connections, whether through social contact or social media, are associated with improved intergroup relations and support for immigration.

\section{Youth and Adults}

Youth were more likely to have pro-immigration attitudes and interethnic friendships than Canadian adults. Comparing the results of this survey to polls conducted by four different agencies (Angus Reid, EKOS, Environics, Leger) reveals that Canadian youth are 2-4 times more likely to support growing immigration than adults, and 6-9 times less likely to oppose inclusive immigration policy (Angus Reid 2019a; EKOS, 2019; Smith, 2019). However, adults who identify as political Liberals have similar rates of pro-immigration attitudes as youth, while NDP and Conservative voters are less supportive of immigration (Smith, 2019; Wright, 2019). This indicates that either youth develop more conservative attitudes as they age, or that this generation is, and will remain, more supportive of immigration. To maintain support for inclusive immigration policy in Canada, it is important to investigate the factors that erode support for immigration, address Canadians' concerns by providing opportunities to confront threat-based perspectives of immigration, increase comfort with ethnocultural diversity, and promote neutral media framing.

Adults are also likely to misinterpret immigrants' country or region of origin, with nearly two-thirds of adults falsely perceiving the Middle East/ North Africa as the most common region of origin for recent immigrants (Angus Reid, 2019a). Youth were more likely to - correctly — name Asia when picturing regions of origin. It is possible that the different perceptions of regions of origin contribute to higher levels of anti-immigrant perspectives among adults, as compared to youth, as immigration from the Middle East/ North Africa may be interpreted as Muslim immigration. As the Muslim population in Canada experiences discrimination and hate crimes (Government of Canada, 2020), it is possible to infer that there is a resistance to the immigration of Muslims, or of groups perceived as Muslims. Youth's qualitative responses also allude to prejudice among older generations: one participant expressed the perception that their peers learn anti-immigrant prejudice from their parents. Another respondent shared that while they have had few experiences of discrimination, "we (BIPOC) still see our parents go through many negative experiences as new Canadians."

\section{Friendships \& Belonging}

Among youth, a sense of belonging was positively correlated with frequent and friendly intergroup contact, number of interethnic friendships, and participation in recreational activitiesrather than inherent personal characteristics such as language, ethnicity, or time in Canada. The insignificant role of personal characteristics is contrary to existing literature (e.g., Berry \& Hou, 2017; Hou et al., 2016; Robinson et al., 2020), and could be due to the low number of immigrant participants and the relatively young ages of immigration among this sample. 
The findings indicate the importance of intergroup contact in promoting integration and provide evidence of the benefits of intergroup contact and intergroup friendships. One pathway to promoting belonging is to create opportunities for intergroup friendship formation. For immigrants, intergroup friendships form the basis of social capital that may have been lost during migration and are linked to higher rates of belonging, wellbeing, academic achievement, and economic success (Rienties \& Nolan, 2014; Robinson et al., 2020). Canadian-born youth benefit from friendships as well, reporting higher feelings of belonging, mental health, and life satisfaction (Hou et al., 2016). Despite the benefits, intergroup friendships are not the norm for Canadian-born youth, consistent with previous research among university students (Robinson et al., 2020). Participants reported challenges making friendships: "settled Canadians stay in their own groups, so unless new Canadians are very outgoing" integration is difficult. "In fact," wrote one respondent, "I see better relationships being built between new Canadians than [between] settled and new Canadians".

These responses support existing literature that finds that although immigrants and international students are eager to socially integrate and form intergroup friendships, settled Canadians are often uninterested (Rienties \& Nolan, 2014; Robinson et al., 2020). Although friendships cannot be forced, there was a significant correlation between frequency of contact and both intergroup and interethnic friendships, indicating that initiatives to promote intergroup contact are likely to support intergroup friendship formation as well.

\section{Understanding Diversity, Threat, and Immigration}

Diversity provides the opportunity for positive intergroup contact and intergroup friendship formation. However, ethnoculturally diverse environments that lack the protective influence of positive intergroup contact may be associated with anti-immigrant attitudes. This study found no significant relationship between the perceived percent of immigrants in schools and levels of intergroup contact, suggesting that intergroup contact is not a passive process: a diverse social environment does not necessarily lead to increased intergroup contact. This finding is supported by existing literature (Bernstein \& Salipante, 2017; Janmaat, 2014; Kiehne, 2019; Robinson et al., 2020). While schools meet the requirements for positive, equal intergroup contact, only youth predisposed to, or encouraged to, initiate contact will likely experience positive effects. Therefore, for prejudice reduction from intergroup contact to be achieved, it is recommended that schools and recreational programs promote opportunities for meaningful intergroup connection and intercultural learning.

If schools fail to support intergroup connections in their increasingly diverse populations, there is a risk that students will experience negative intergroup contact that may develop into negative intergroup attitudes (Esses, 2021). The results indicated that perceptions of diversity were negatively correlated with support for immigration: youth who estimated a higher percentage of immigrants in Canada were less likely to support more immigration. Immigration can pose a threat to the cultural values of the settled population (Callens et al., 2019) and, "the larger the proportion of the out-group in a given population is, the more the dominant group will feel threatened in its privileged position" (Janmaat, 2014, p. 812). Aligned with the multiculturalism hypothesis, the results of this study indicate an association between this decreased sense of cultural security and decreased support for immigration (Berry et al., 2021; Esses, 2021).

Youth's qualitative responses provided further insight on the link between diversity and anti-immigrant perspectives. While the majority of youth reported friendly intergroup relations and supported increased immigration, several participants expressed feelings of threat. One participant wrote that the "lack of cultural assimilation of newcomers has left me feeling estranged in my own 
country". This response expresses a sense of both decreased belonging as a result of the relative increase in cultural diversity and a pro-assimilation perspective. Another participant shared: "While I think diversity is what can make our country special, I sometimes worry about how that affects our Canadian culture. Because change is good, but it's scary". Discomfort with diversity connects the experiences of, and prejudice directed at, visible minorities and immigrants. Resistance to immigration may be related to the changing source countries of immigration: while Asia remains the most common source continent, the 2016 census found that Africa is now the second most common region of origin, replacing Europe (Statistics Canada, 2017b). Non-white immigrants pose increased threat to settled Canadians, as they challenge both the ethnic and sociocultural norms. Supporting this concept, Berry at el (2006) found that Canadians have more favourable attitudes towards racial minorities already in Canada than immigrants of the same minority, "indicating relatively less willingness to accept immigrants compared to those already settled in Canada" ( $\mathrm{p}$. 724).

\section{Intergroup Relations and Acculturation}

Immigration alters Canada's demographic composition, cultural practices, and social customs. For settled Canadians who fail to integrate with immigrants, increases in the relative power of unfamiliar people, customs, and values may be experienced as a threat to the sociocultural status quo. While this does not necessarily indicate anti-immigration perspectives, perceptions of threat must be addressed in order to prevent their evolution into prejudice. Expectations that immigrants will assimilate is another risk factor for prejudice: assimilation may permit resentment when immigrants do not adopt Canadian values (Esses, 2021). In addition, assimilation does not promote acts of inclusion or multicultural acceptance (Naffi, 2017).

Hou and colleagues (2016) argue that belonging is a measure of integration. By this, and more traditional measures such as frequency of intergroup contact, both Canadian-born and immigrant youth are relatively well integrated. Although the groups have similar rates of frequency and perceived friendliness of intergroup contact, new immigrants were significantly more likely to have social circles with a majority of intergroup contact. This finding suggests that immigrant youth in Canada are not adopting a separationist acculturation strategy and forming isolated cultural communities and contradicts the narrative pressuring immigrants to integrate. Immigrants are not assimilated - each community, family, or individual remains culturally unique - they are integrated.

Although Canadian-born youth reported high levels of support for immigration and frequent intergroup contact, their low rates of intergroup friendships may indicate failure to meaningfully integrate and may be contributing to the feelings of cultural estrangement expressed by at least one participant in this study. As Canada becomes increasingly diverse and immigrant Canadians are welcomed into meaningful social positions at the local, provincial, and federal levels, unintegrated Canadians are likely to experience estrangement (i.e. decreased belonging and familiarity) and threat. These negative intergroup experiences are likely to translate into prejudice and discrimination towards immigrants and visible minorities. In order to prevent intergroup conflict, it is vital to actively promote integration and multiculturalism among Canadians. Potential pathways for achieving this include contact-based integration support and a reframing of integration in research, policy, and practice. As well as integration research that investigates the experiences of the dominant group, there is a need for multicultural education in schools and a shift in Canadian discourse and media. 


\section{Sources of Information}

This study found that using the news (print, radio, TV, or websites) as a source immigrationrelated information predicted lower support for immigration. The negative impact of the news may be because immigration coverage so often sensationalizes and exaggerates immigration; previous literature found that media coverage that describes immigration arriving in "floods" and "waves" or emphasizes crises and conflict is linked to support for restrictive immigration policy (Jimenez et al., 2021; Wallace, 2018). Conversely, this study found that social media use for immigrationrelated information positively predicted pro-immigration attitudes, in contradiction to fears that social media contributes to xenophobia and plays a "powerful role in spreading hate speech and bigotry", particularly among young people (Government of Canada, 2020, p. 5). The positive impact could be because social media acts as a form of intergroup contact which provides the opportunity for immigrants to present themselves as individuals, decreasing the likelihood of "othering" by settled Canadians.

These findings indicate that the framing of news articles and established journalism merits revision and examination; more generally, it indicates a need for a renewed attention towards the existing and accepted systems that encourage division and discrimination, as well as monitoring of the influences of new forms of media. It should also be noted that the impacts of negative media are thought to be particularly strong among individuals with low levels of personal contact with immigrants (Wallace, 2018). As such, addressing perceptions of threat through re-framing immigration discourse and promoting contact-based interventions are interrelated strategies to address anti-immigrant prejudice and promote social cohesion.

\section{Recommendations}

While this study examined intergroup relations between Canadian youth, the core theories of intergroup relations applied in this paper are applicable in culturally diverse societies around the world (Berry et al., 2021). As immigration continues to change population demographics in a wide range of countries, the recommendations generated in from the results of this study can be applied across national contexts. Promoting positive intergroup relations will require interdisciplinary support and engagement from educators, settlement workers, policymakers, and the journalists and scholars that contribute to discourse related to immigration.

Reframing integration as the responsibility of both immigrant and settled youth and creating opportunities for intergroup contact are important to reduce anti-immigrant sentiment and promote intergroup harmony. Intergroup contact can be encouraged in youth programming in schools, extracurricular programs, community centers, and settlement organizations. Specifically, programs should encourage socioculturally diverse participation, actively promote intergroup contact (e.g., create diverse sports teams, or have students work in intergroup pairs), and build multicultural awareness (e.g., using diverse models and inspirations for arts and cultural programs, forming cultural or international clubs in schools, adding cultural lenses to social studies and history classes).

Schools can support integration by promoting a positive environment where friendships are encouraged. and intergroup relations are modeled between a diverse teaching and administrative staff. Another action is to incorporate a multicultural lens into classes, particularly English, history, and social studies, planning lessons that include international perspectives. After-school programs and school-based extracurricular activities should work towards diversity and intergroup contact by promoting accessibility for immigrants, a safe and inclusive environment and efforts to recruit 
a diversity of ethnocultural participants. In the media, including public-facing policy briefs, it is important to challenge assimilation-based assumptions and rhetoric. Journalists and news organizations, more specifically, must critically examine their language and framing of immigration content and eliminate language that exaggerates the proportions of immigrants arriving, living, or thriving: working to accurately and respectfully portray the stories of immigration is a priority.

Finally, researchers studying integration, immigration, and acculturation must work to include the experiences of settled communities. Although focusing on the integration process of minority groups is extremely valuable and informs immigration and settlement programs, including the perceptions of the dominant group is necessary for a full understanding of intergroup relations and the acculturation process. In addition, understanding the changes and experiences of the dominant group creates the possibility of developing programs for settled communities that may need support adapting to changing ethnonational demographics. Finally, examining the acculturation experiences and perceptions of both groups allows for investigation into the connections between threat, diversity, prejudice, and integration.

\section{Limitations}

The low number of immigrant participants was a limitation of this study, exacerbated by the unexpected numbers of immigrants that self-identified as "settled Canadians". However, the self-identification provided the opportunity to investigate the variables influencing the immigrant youths' self-identification. This survey is also limited by the low male participation rate. Additionally, because this study used Instagram advertisements, the sample is limited to Instagram users and introduced the possibility of self-selection bias. Several results in the study, including rates and mean numbers of intergroup friendship and participation in extracurricular activities, are consistent with existing research, however, replication of this study with a representative sample of youth is recommended.

\section{Conclusion}

This study found that youth are more supportive of inclusive immigration policy than adult Canadians. Support for immigration was not significantly affected by intergroup contact or personal characteristics, but it was negatively correlated with perceptions of diversity in Canada. The qualitative responses indicate that, for some youth, immigration is perceived as a threat to cultural values: more diversity in Canada may be viewed as more threatening. This might explain why learning about immigration from the news, which often emphasizes or exaggerates rates of immigration, is linked with anti-immigrant perspectives.

Overall, Canadian youth have positive intergroup relations: youth have frequent intergroup contact, are likely to perceive intergroup relations as friendly, have several interethnic friendships, and overwhelmingly support immigration. In particular, immigrant youth are well-integrated and report high levels of belonging. Canadian-born youth, while reporting frequent intergroup contact, very rarely have social circles with a majority of intergroup friendships. The more homogenous friendships of Canadian-born participants were correlated with lower feelings of belonging, which seems to explain the higher perceptions of belonging among new-immigrant youth than their Canadian-born peers. These findings indicate that Canadian-born youth could benefit from increased integration support and interventions which promote diverse friendships. Ultimately, supporting intergroup friendship formation, addressing anti-immigration rhetoric in the media, and 
developing integration supports for non-immigrant youth are promising pathways to increase comfort with diversity, foster positive intergroup relationships, and improve feelings of belonging for youth in culturally diverse societies.

\section{Highlights \& Implications}

- Youth have frequent and friendly intergroup contact, but immigrant youth are much more likely to have intergroup friendships than their Canadian-born peers.

- Intergroup contact, perceived friendliness of intergroup relations, and intergroup friendships predicted feelings of belonging.

- Perceptions of high levels of diversity predicted less support for immigration.

- Relying on the news for information about immigration predicted lower support for immigration, while relying on social media predicted higher support.

- These results suggest that promoting intergroup contact and friendships are important to creating feelings of belonging in culturally diverse societies.

- Schools are well-placed to provide opportunities for positive intergroup contact and human-centric information about immigration, which are promising pathways to creating social cohesion and positive intergroup relations in ethnoculturally diverse communities.

\section{Funding Details}

This work was supported by Research Manitoba under Grant 4295.

\section{Disclosure Statement}

There are no declarations of interest to declare.

\section{References}

Allport, G. W. (1954). The nature of prejudice. Addison-Wesley.

Angus Reid Institute. (2019a). Immigration: Half back current targets, but colossal misperceptions, pushback over refugees, cloud debate. http://angusreid.org/wpcontent/uploads/2019/10/2019.10.04_Immigration-Views.pdf

Angus Reid Institute. (2019b). Canadians are divided on the actual effect of immigration. http://angusreid.org/canadians-are-divided-on-the-actual-effect-of-immigration/

Bernstein, R., \& Salipante, P. (2017). Intercultural comfort through social practices: Exploring conditions for cultural learning. Frontiers in Education, 2. https://doi.org/10.3389/feduc.2017.00031

Berry, J. W., \& Hou, F. (2017). Acculturation, discrimination and wellbeing among second generation of immigrants in Canada. International Journal of Intercultural Relations, 61, 29-39. https://doi.org/10.1016/j.ijintrel.2017.08.003

Berry, J. W., Lepshokova, Z., Grigoryev, D., Annis, R. C., Au, A. K. Y., Bano, S., Boehnke, K., Buholzer, A., Brylka, A., Chen, S. X., Dandy, J., Dunn, K., Van Egmond, M., Galyapina, V., Gibson, R., Grad, H., Gui, Y., Hanke, K., Jasinskaja-Lahti, I., ... Hui, B. P. H. (2021). How shall we all live together?: Meta-analytical review of the mutual intercultural relations in plural societies project. Applied Psychology. https://doi.org/10.1111/apps.12332 
Berry, J., Phinney, J., Sam, D., \& Vedder, P. (2006). Immigrant youth: Acculturation, identity, and adaptation. Applied Psychology, 55(3), 303-332. https://doi.org/10.1111/j.14640597.2006.00256.x

Callens, M.S., Meuleman, B., \& Marie, V. (2019). Contact, perceived threat, and attitudes toward assimilation and multiculturalism: Evidence from a majority and minority perspective in Luxembourg. Journal of Cross-Cultural Psychology, 50(2), 285-310. https://doi.org/10.1177/0022022118817656

Canadian Multiculturalism Act. (1985). R.S., c. 24 (4th Supplement). Government of Canada. https://laws-lois.justice.gc.ca/eng/acts/c-18.7/page-1.html

Cohen, B. J. (2016). Fostering resilience and compassion among refugees and their peers. [Masters Thesis, University of Toronto]. Tspace University of Toronto. https://tspace.library.utoronto.ca/bitstream/1807/72676/3/Cohen_Brittany_J_201606_MA _thesis.pdf

EKOS Politics. (2019). Increased polarization on attitudes to immigration reshaping the political landscape in Canada. https://www.ekospolitics.com/index.php/2019/04/increasedpolarization-on-attitudes-to-immigration-reshaping-the-political-landscape-in-canada/

Esses, V. M. (2021). Prejudice and discrimination toward immigrants. Annual Review of Psychology, 72(1), 503-531. https://doi.org/10.1146/annurev-psych-080520-102803

Gallucci, A. (2016). A phenomenological investigation of newcomer youths' experiences of integration into high school and transition to post-secondary education in Canada. [Unpublished Master's Thesis, University of Calgary].

Government of Canada. (2020). Annual Report on the Operation of the Canadian Multiculturalism Act 2018-19. https://www.canada.ca/en/canadian-heritage/corporate/publications/plansreports/annual-report-canadian-multiculturalism-act-2018-2019.html

Hou, F., Schellenberg, G., \& Berry, J. (2016, October 18). Patterns and determinants of immigrants' sense of belonging to Canada and their source country. (Analytical Studies Branch Research Paper Series, No. 383). Statistics Canada. https://www150.statcan.gc.ca/n1/pub/11f0019m/11f0019m2016383-eng.pdf

Immigration and Refugee Protection Act [Canada], SC 2001, c. 27 (2001). https://laws.justice.gc.ca/eng/acts/i-2.5/

Janmaat, J. (2014). Do ethnically mixed classrooms promote inclusive attitudes towards immigrants everywhere? A study among native adolescents in 14 countries. European Sociological Review, 30(6), 810-822. https://doi.org/10.1093/esr/jcu075

Jimenez, T., Arndt, J., \& Landau, M.J. (2021). Walls block waves: Using an inundation metaphor of immigration predicts support for a border wall. Journal of Social and Political Psychology, 9(1), 159-171. https://doi.org/10.5964/jspp.6383

Kaufmann, L. (2021). Integration in Canada: A systematic review of the youth experience. International Journal of Intercultural Relations, 84, 52-64. https://doi.org/10.1016/j.ijintrel.2021.06.010

Kiehne, E. (2019). Pathways to support for integrationist immigration policymaking among USborn whites: Testing deprovincialization hypothesis of the intergroup contact theory and the role of Latino immigrant threat perception. [Unpublished Doctoral Dissertation]. University of Arizona.

Kiehne, E., \& Ayón, C. (2016). Friends or foes: The impact of political ideology and immigrant friends on anti-immigrant sentiment. Journal of Sociology and Social Welfare, 43(3), 135154. 
Naffi, N. (2017). Learning about oneself: An essential process. [Doctoral dissertation, Concordia University]. Spectrum Library.

Neuman, K. (2019). Canadian public opinion about immigration and refugees. Environics Institute for Survey Research. https://www.environicsinstitute.org/projects/projectdetails/canadian-public-opinion-on-immigration-and-refugees

Pettigrew, T., \& Tropp, L. (2006). A meta-analytic test of intergroup contact theory. Journal of Personality and Social Psychology, 90(5), 751-783. https://doi.org/10.1037/00223514.90.5.751.

Pettigrew, T., Tropp, L., Wagner, U., \& Christ, O. (2011). Recent advances in intergroup contact theory. International Journal of Intercultural Relations, 35(3), 271-280. https://doi.org/10.1016/j.ijintrel.2011.03.00.

Reitz, J. G., \& Banerjee, R. (2007). Racial inequality, social cohesion and policy issues in Canada. In K. Banting, T. J. Courchene, \& F. L. Seidle (Eds.), Belonging? Diversity, recognition and shared citizenship in Canada (pp. 1-57). QC: Institute for Research on Public Policy.

Rienties, B \& Nolan, E. (2014). Understanding friendship and learning networks of international and host students using longitudinal Social Network Analysis. International Journal of Intercultural Relations, 41, 165-180. https://doi.org/10.1016/j.ijintrel.2013.12.003

Robinson, O., Somerville, K., \& Walsworth, S. (2020). Understanding friendship formation between international and host-national students in a Canadian university. Journal of International and Intercultural Communication, 13(1), 49-70. https://doi.org/10.1080/17513057.2019.1609067

Smith, S. (2019, May 1). Canadian public opinion on immigration, refugees 'remarkably steady', new survey finds. CIC News. https:/www.cicnews.com/2019/04/majority-of-canadiansmaintain-positive-views-of-immigration-new-survey-finds-0412240.html\#gs.lu9q91

Statistics Canada. (2017a). Immigration and ethnocultural diversity: Key results from the 2016 census. https://www150.statcan.gc.ca/n1/daily-quotidien/171025/dq171025b-eng.pdf

Statistics Canada. (2017b). Focus on Geography Series, 2016 Census. Statistics Canada Catalogue no. 98-404-X2016001. https://www12.statcan.gc.ca/census-recensement/2016/as-sa/fogsspg/Facts-can-eng.cfm?Lang=Eng\&GK=CAN\&GC=01\&TOPIC $=7$

Stephan, W.G. \& Renfro, C.L. (2002). The role of threat in intergroup relations. In D. M. Mackie \& E. R. Smith (Eds.), From prejudice to intergroup emotions (pp. 191-207). New York: Psychology Press.

Wallace, R. (2018). Contextualizing the crisis: The Framing of Syrian refugees in Canadian print media. Canadian Journal of Political Science, 51(2), 207-231. https://doi.org/10.1017/S0008423917001482

Wright, T. (2019, June 16). Poll suggests majority of Canadians favour limiting immigration levels. The Canadian Press. https://www.cbc.ca/news/politics/canadians-favour-limitingimmigration-1.5177814

\section{Notes on Contribution}

Lily Kaufmann is a social science researcher with a Master of Human Rights from the University of Manitoba. Her current research focus is on the role of positive intergroup relations, prejudice reduction, and social acceptance in the fulfilment of social and cultural rights. In particular, she is interested in addressing social inequity through addressing negative perceptions and promoting prosocial attitudes within dominant communities. 
Kaufmann, L.

\section{Appendix}

\section{Appendix A}

\section{Correlation Matrix}

\begin{tabular}{|c|c|c|c|c|c|c|c|c|c|c|c|c|c|}
\hline \multicolumn{14}{|c|}{ Correlations } \\
\hline & & Belonging & Gender & Indigenous & $\begin{array}{l}\text { Paricipant } \\
\text { Self ID group }\end{array}$ & $\begin{array}{l}\text { English as a } \\
\text { First } \\
\text { Language }\end{array}$ & $\begin{array}{l}\text { Time spoken } \\
\text { English }\end{array}$ & $\begin{array}{l}\text { Time in } \\
\text { Canada }\end{array}$ & $\begin{array}{c}\text { Extracurricul } \\
\text { ars }\end{array}$ & $\begin{array}{l}\text { Frequency of } \\
\text { Intergroup } \\
\text { Contact }\end{array}$ & $\begin{array}{l}\text { Intergroup } \\
\text { Frienliness: } \\
\text { Personal } \\
\text { Interactions }\end{array}$ & $\begin{array}{l}\text { Intergroup } \\
\text { Friendliness: } \\
\text { School }\end{array}$ & $\begin{array}{l}\text { Perceived } \\
\text { School } \\
\text { Diversity }\end{array}$ \\
\hline \multirow[t]{3}{*}{ Belonging } & Pearson Correlation & 1 & .017 & $-.160^{*}$ & -.009 & .097 & -.304 & -.065 & $-.184^{\circ}$ & $.237^{4}$ & $.202^{* 1}$ & $.186^{\circ}$ & -.055 \\
\hline & Sig. (2-tailed) & & .831 & .038 & .907 & .212 & .080 & .401 & .017 & .005 & .009 & .022 & .481 \\
\hline & $\mathrm{N}$ & 168 & 168 & 168 & 166 & 168 & 34 & 168 & 168 & 141 & 165 & 152 & 166 \\
\hline \multirow[t]{3}{*}{ Gender } & Pearson Correlation & .017 & 1 & $.171^{\circ}$ & .006 & -.057 & .071 & .090 & -.058 & -.051 & .111 & -.093 & .060 \\
\hline & Sig. (2-tailed) & .831 & & .026 & .936 & .465 & .689 & .244 & .453 & .548 & .155 & .253 & .441 \\
\hline & $\mathrm{N}$ & 168 & 168 & 168 & 166 & 168 & 34 & 168 & 168 & 141 & 165 & 152 & 166 \\
\hline \multirow[t]{3}{*}{ Indigenous } & Pearson Correlation & $-.160^{\circ}$ & $.171^{\circ}$ & 1 & -.120 & -.139 & .280 & .040 & .029 & .049 & -.087 & -.072 & -.048 \\
\hline & Sig. (2-tailed) & .038 & .026 & & .123 & .072 & .109 & .609 & .706 & .567 & .265 & .378 & .542 \\
\hline & $\mathrm{N}$ & 168 & 168 & 168 & 166 & 168 & 34 & 168 & 168 & 141 & 165 & 152 & 166 \\
\hline \multirow[t]{3}{*}{ Participant Self ID group } & Pearson Correlation & -009 & .006 & -.120 & 1 & $.456^{\prime \prime}$ &,$- 463^{* \prime}$ & .054 & .038 & -.143 &,- 081 & .027 & -.047 \\
\hline & Sig. (2-tailed) & .907 & .936 & .123 & & .000 & .006 & .488 & .624 & .094 & .304 & .746 & .551 \\
\hline & $\mathrm{N}$ & 166 & 166 & 166 & 166 & 166 & 34 & 166 & 166 & 139 & 163 & 150 & 164 \\
\hline \multirow{3}{*}{$\begin{array}{l}\text { English as a First } \\
\text { Language }\end{array}$} & Pearson Correlation & .097 & -.057 & -.139 & $.456^{* *}$ & 1 & .6 & .063 & -.013 & -.089 & -.015 & .000 & -.071 \\
\hline & Sig. (2-tailed) & .212 & .465 & .072 & .000 & & .000 & .420 & .871 & .293 & .844 & .997 & .365 \\
\hline & $\mathrm{N}$ & 168 & 168 & 168 & 166 & 168 & 34 & 168 & 168 & 141 & 165 & 152 & 166 \\
\hline \multirow[t]{3}{*}{ Time Speaking English } & Pearson Correlation & -.304 & .071 & .280 & $-.463^{*}$ & 6 & 1 & .088 & .091 & .342 & -.072 & .240 & .083 \\
\hline & Sig. (2-tailed) & .080 & .689 & .109 & .006 & .000 & & .620 & .611 & .070 & .685 & .193 & .639 \\
\hline & $\mathrm{N}$ & 34 & 34 & 34 & 34 & 34 & 34 & 34 & 34 & 29 & 34 & 31 & 34 \\
\hline \multirow[t]{3}{*}{ Time in Canada } & Pearson Correlation & -.065 & .090 & .040 & .054 & .063 & .088 & 1 & -.039 & -.163 & .061 & -.046 & -.049 \\
\hline & Sig. (2-talled) & .401 & .244 & .609 & .488 & .420 & .620 & & .612 & .053 & .439 & .577 & .531 \\
\hline & $\mathrm{N}$ & 168 & 168 & 168 & 166 & 168 & 34 & 168 & 168 & 141 & 165 & 152 & 166 \\
\hline \multirow[t]{3}{*}{ Extracurficulars } & Pearson Correlation & $.184^{\circ}$ & -.058 & .029 & .038 & -.013 & .091 & -.039 & 1 & -.007 & .011 & .038 & .091 \\
\hline & Sig. (2-tailed) & .017 & .453 & .706 & .624 & .871 & .611 & .612 & & .937 & .883 & .640 & .243 \\
\hline & $\mathrm{N}$ & 168 & 168 & 168 & 166 & 168 & 34 & 168 & 168 & 141 & 165 & 152 & 166 \\
\hline \multirow{3}{*}{$\begin{array}{l}\text { Frequency of Intergroup } \\
\text { Contact }\end{array}$} & Pearson Correlation & $.237^{* \prime}$ & -.051 & -.049 & -.143 & -.089 & .342 & -.163 & -.007 & 1 & $.260^{* \prime}$ & $.180^{\circ}$ & .111 \\
\hline & Sig. (2-tailed) & .005 & .548 & .567 & .094 & .293 & .070 & .053 & .937 & & .002 & .037 & .194 \\
\hline & N & 141 & 141 & 141 & 139 & 141 & 29 & 141 & 141 & 141 & 140 & 135 & 139 \\
\hline \multirow{3}{*}{$\begin{array}{l}\text { Intergroup Friend liness: } \\
\text { Personal Interactions }\end{array}$} & Pearson Correlation & $.202^{\prime \prime}$ & .111 & -.087 & -.081 & -.015 & -.072 & .061 & .011 & $.260^{\circ \prime}$ & 1 & $.438^{\prime \prime}$ & -.046 \\
\hline & Sig. (2-tailed) & .009 & .155 & .265 & .304 & .844 & .685 & .439 & .883 & .002 & & .000 & .558 \\
\hline & $\mathrm{N}$ & 165 & 165 & 165 & 163 & 165 & 34 & 165 & 165 & 140 & 165 & 150 & 163 \\
\hline \multirow{3}{*}{$\begin{array}{l}\text { Intergroup Friend liness: } \\
\text { School }\end{array}$} & Pearson Correlation & $.186^{\circ}$ & -.093 & -.072 & .027 & .000 & .240 &,- 046 & .038 & $.180^{\circ}$ & $.438^{* \prime}$ & 1 & -144 \\
\hline & Sig. (2-tailed) & .022 & .253 & .378 & .746 & .997 & .193 & .577 & .640 & .037 & .000 & & .079 \\
\hline & $\mathrm{N}$ & 152 & 152 & 152 & 150 & 152 & 31 & 152 & 152 & 135 & 150 & 152 & 150 \\
\hline \multirow{3}{*}{$\begin{array}{l}\text { Perceived School } \\
\text { Diversity }\end{array}$} & Pearson Correlation & -.055 & .060 & -.048 & -.047 & -.071 & .083 & -.049 & .091 & .111 & -.046 & -.144 & 1 \\
\hline & Sig. (2-tailed) & .481 & .441 & .542 & .551 & .365 & .639 & .531 & .243 & .194 & .558 & .079 & \\
\hline & $\mathrm{N}$ & 166 & 166 & 166 & 164 & 166 & 34 & 166 & 166 & 139 & 163 & 150 & 166 \\
\hline \multirow{3}{*}{$\begin{array}{l}\text { Majority intergroup } \\
\text { friend ships }\end{array}$} & Pearson Correlation & $.185^{\circ}$ &,- 005 & .128 & $-.283^{\prime \prime}$ & $-369^{\prime \prime}$ & .242 & $.187^{\circ}$ & -.005 &,$- 180^{\circ}$ & .019 & .015 & -.025 \\
\hline & Sig. (2-tailed) & .025 & .948 & .123 & .001 & .000 & .189 & .023 & .955 & .044 & .825 & .867 & .763 \\
\hline & $\mathrm{N}$ & 147 & 147 & 147 & 145 & 147 & 31 & 147 & 147 & 126 & 144 & 134 & 145 \\
\hline
\end{tabular}

